\title{
DENSITY FUNCTIONAL PREDICTION OF THE STRUCTURAL, ELASTIC, ELECTRONIC, AND THERMODYNAMIC PROPERTIES OF THE CUBIC AND HEXAGONAL $(c, h)-\mathrm{Fe}_{2} \mathrm{Hf}$
}

\author{
M. Hamici ${ }^{1}$, T. Chihi ${ }^{2}$, M.A Ghebouli ${ }^{2}$,M. Fatmi ${ }^{2, *}$, B. Ghebouli ${ }^{3}$,Sameh I. \\ Ahmed $^{4}$ \\ ${ }^{1}$ Dosage Analysis and Characterization Laboratory (DAC), University Farhet Abbas of \\ Setif 1, 19000, Algeria \\ ${ }^{2}$ Research Unit on Emerging Materials (RUEM), University Farhet Abbas of Setif 1, \\ 19000, Algeria \\ ${ }^{3}$ Laboratory of Studies Surfaces and Interfaces of Solids Materials, Department of \\ Physics, Faculty of Sciences, University Ferhat Abbas of Setif 1, 19000, Algeria \\ ${ }^{4}$ Department of Physics, College of Science, Taif University, P.O. Box 11099, Taif \\ 21944, Saudi Arabia
}

Received 23.03.2021

Accepted 09.06.2021

\begin{abstract}
The structural, elastic, electrical, and thermodynamic characteristics of $\mathrm{Fe}_{2} \mathrm{Hf}$ cubic and hexagonal phases with space group $\mathrm{Fd}-3 \mathrm{~m}$ and $\mathrm{P} 63 / \mathrm{mmc}$ are presented using the generalized gradient approximations. The k-points mesh density and plane-wave energy cut-off accomplish the energy convergence. The computed equilibrium parameters are closer to the theoretical data. The elastic tensor and crystal anisotropy of ultraincompressible $\mathrm{Fe}_{2} \mathrm{Hf}$ are computed in a wide pressure range. The isothermal and adiabatic bulk modulus, as well as the heat capacity of $\mathrm{Fe}_{2} \mathrm{Hf}$ is successfully calculated utilizing the quasi-harmonic Debye Model. The Fd-3m and P63/mmc $\mathrm{Fe}_{2} \mathrm{Hf}$ structures are stable in the studied pressure range.
\end{abstract}

Keywords: elastic stability; thermodynamic properties; $\mathrm{Fe}_{2} \mathrm{Hf}$ compound. 


\section{Introduction}

$\mathrm{Fe}_{2} \mathrm{Hf}$ structures have not been produced in crystalline form. We propose the cubic and hexagonal structures. The strength and hardness of materials are determined from elastic constants under pressure. These crucial parameters determine the crystal's reaction to external forces, as defined by the bulk and shear modulus. The elastic characteristics of cubic and hexagonal structures are also obtained. The structural, elastic and thermodynamic parameters of hexagonal $\mathrm{Fe}_{2} \mathrm{Hf}$ structure under pressure were treated for the first time. Koki Ikeda et al. [1] investigated the structure and magnetism in the iron hafnium system. The conclusion is that hexagonal $\mathrm{MgZn}_{2}$-type $\mathrm{Fe}_{2} \mathrm{Hf}$ and cubic $\mathrm{MgCu}_{2}$-type $\mathrm{Fe}_{2} \mathrm{Hf}$ exist above $1673 \mathrm{~K}$ and below $1273 \mathrm{~K}$. S. Kobayashi et al. [2-3] observed periodic arranged rows of fine $\mathrm{Fe}_{2} \mathrm{Hf}$ Laves phase particles produced in a $9 \%$ chromium ferritic matrix. J. Belosevic-Cavor et al. [4] investigated the magnetic characteristics, Mossbauer Effect, and first-principles computations of $\mathrm{Fe}_{2} \mathrm{Hf}$ with a $\mathrm{C} 14$ type structure in the laves phase. Masao Takeyama [5] discovered the hexagonal lattice for $\mathrm{Fe}_{2} \mathrm{Hf}$ with space group $\mathrm{P} 63 / \mathrm{mmc}\left(\mathrm{N}_{0}\right.$ 194). $\mathrm{Fe}_{2} \mathrm{Hf}$ has the $\mathrm{MgCu}_{2}$ type $\mathrm{C} 15$ cubic structure with a narrow content range around the stoichiometry. It also crystallizes in the $\mathrm{MgZn}_{2}$ (C14) hexagonal structural type. The hexagonal phase appears along the dominant cubic structure. The aim of this work is to present a theoretical investigation of the structural and thermodynamic properties of cubic and hexagonal $\mathrm{Fe}_{2} \mathrm{Hf}$ structures. The cubic $\mathrm{Fe}_{2} \mathrm{Hf}$ (hexagonal $\mathrm{Fe}_{2} \mathrm{Hf}$ ) structure has the space group 227, $F d-3 m$ and $\mathrm{Cu}_{2} \mathrm{Mg}$-type (194, P63/mmc and $\mathrm{Zn}_{2} \mathrm{Mg}$-type). The non-equivalent atoms are $\mathrm{Fe}(0.625,0.625,0.625), \mathrm{Hf}(0,0,0)$ and lattice constant $\mathrm{a}=6.882 \AA\left[\mathrm{Fe}_{1}(0,0,0), \mathrm{Fe}_{2}(0.8,0.6,0.25), \mathrm{Hf}(1 / 3,2 / 3,0.06)\right.$ and lattice parameters $\mathrm{a}=\mathrm{b}=4.968 \AA$, $\mathrm{c}=8.098 \AA]$ for cubic $\mathrm{Fe}_{2} \mathrm{Hf}$ (hexagonal $\mathrm{Fe}_{2} \mathrm{Hf}$ ).

\section{Computational details}

We use CASTEP, PWG and GGA as exchange-correlation potential. Without taking account the spin polarized, we must investigate and examine the convergence of calculated total energies with respect to the plane wave cut-off $\mathrm{E}_{\text {cut }}=380 \mathrm{eV}\left(\mathrm{E}_{\mathrm{cut}}=385\right.$ $\mathrm{eV}$ ) in the cubic (hexagonal) phase as reported in Fig.1 (a) and (b) respectively.

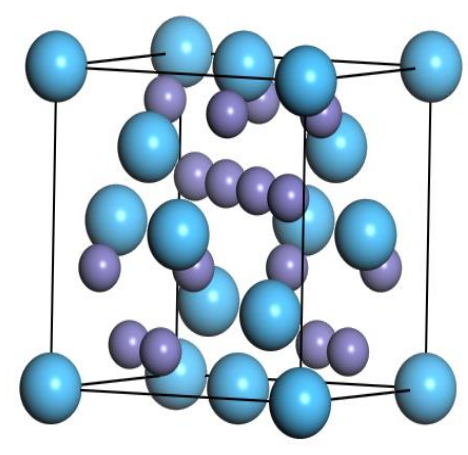




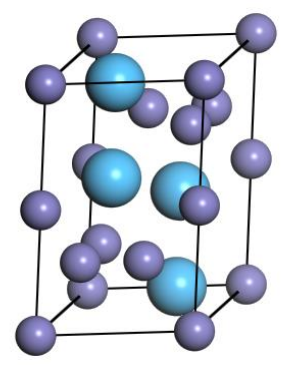

Fig. 1. Unit-cell of $\mathrm{Fe}_{2} \mathrm{Hf}$ cubic and hexagonal crystal, the large and small balls represent $\mathrm{Hf}$ and $\mathrm{Fe}$ atoms, respectively.

\section{Structural properties}

We use first-principles computations to investigate the structural, elastic, electrical, and thermodynamic properties of $\mathrm{Fe}_{2} \mathrm{Hf}$ with cubic (hexagonal) structure under pressures up to $10 \mathrm{GPa}(15 \mathrm{GPa})$. The elastic characteristics of cubic and hexagonal $\mathrm{Fe}_{2} \mathrm{Hf}$ under pressure are examined, where the mechanical stability is ensured. The Debye model is used to derive thermodynamic parameters such as heat capacity, thermal expansion and Debye temperature. However, it is difficult to study it experimentally because of the small size and time scale at which the functional properties appeared. Theoretical modeling offers a way to overcome these difficulties through "virtual experiments" that can enable us to explore the phase space. The DFT is widely used in quantum computation in condensed matter physics [6-8]. DFT is a general-purpose computational method, and can be applied to most systems. Although density functional theory is more precise and perfect in theory, it involves various approximations in practice, [9-11], and mesh size for Brillouin zone for plane-wave basis [12-14]. More include plane waves; the better the wave function is modeled. The k-points mesh controls the BZ integration, can play a huge role in the quality of the results and heavily depends on the number of these points on the mesh-grid, especially for metals. The plane wave basis set, in the DFT wave function is expanded in terms of its periodicity and case of use. The DFT wave function is expanded in terms of a plane wave basis set [15]:

$$
\psi(r)=\sum_{G} C_{G} e^{i(G+K) r}
$$

And the cut-off energy $\mathrm{E}_{\text {cut }}$ is defined as:

$$
\begin{aligned}
& E_{\text {cut }}=\frac{\hbar^{2}}{2 m}\left|G_{\text {cut }}\right|^{2} \\
& |G+K|<E_{\text {cut }}
\end{aligned}
$$

The Fig. 1 represents total energy as a function of k-points. The convergence has been achieved in the k-points sampling of $1 \times 1 \times 1$ for total energy convergence tolerance $(1.0$ $10^{-6} \mathrm{eV} /$ atom). 
The rest of this paper is structured as follows. The computational method is described in section 2. The results and some discussions of structural, elastic and thermodynamic properties of $\mathrm{Fe}_{2} \mathrm{Hf}$ under pressure are presented and compared with available experimental and theoretical data in section 3. The large and small balls of $\mathrm{Fe}$ and Hf atoms are shown in Fig. 2. The convergence of calculated number of points is $6 \times 6 \times 6$ of $c-\mathrm{Fe}_{2} \mathrm{Hf}$ and $h$ - $\mathrm{Fe}_{2} \mathrm{Hf}$, as shown in Fig.3. We show the plot of energy versus volume for cubic and hexagonal $\mathrm{Fe}_{2} \mathrm{Hf}$ in Fig.4 (a) and (b). The calculations of the structural, elastic, and thermodynamic properties were performed using the CASTEP code $[16,17]$. Fe (3d64 s2) and Hf (4f145 d26 s2) orbitals are considered as valence electrons. The Brillouin zone sampling was done using the Monkhorst-Pack mesh $6 \times 6 \times 6$ for cubic and hexagonal structures of $\mathrm{Fe}_{2} \mathrm{Hf}$ [18]. The most stable structure requires its optimization using the Broyden-Fletcher-Goldfarb-Shenno (BFGS) minimization technique. Setting self-consistent convergence conditions: total energy per atom was less than $0.2 \mathrm{eV}$, force per atom was less than $0.05 \mathrm{eV}$, offset tolerance was less than $0.0002 \mathrm{~A}$, and stress bias was less than $0.1 \mathrm{GPa}$. It should be noted that the predicted total energies of cubic and hexagonal (c- h) - $\mathrm{Fe}_{2} \mathrm{Hf}$ structures have negative values, indicating an exothermic reaction, as shown in Table 1. According to the total energies, hexagonal structure is more stable than cubic structure.

Table 1. The calculated lattice constant $(\AA)$, volumes $\left(\AA^{3}\right)$, bulk modulus, elastic constants, shear modulus, Young's modulus, $B / G$ ratio, density, sound velocities, and Debye temperature for $(c-h)-\mathrm{Fe}_{2} \mathrm{H} f$ structures.

\begin{tabular}{lll}
\hline & Cubic structure & Hexagonal structure \\
\hline Cuttofenegy $(\mathrm{eV})$ & 380 & 385 \\
KxKxK & $6 \times 6 \times 6$ & $6 \times 6 \times 6$ \\
Total energy $(\mathrm{eV})$ & -4280.10 & -8560.42 \\
$\mathrm{a}(\AA)$ & 4.883 & $4.858(4.968)$ \\
$\mathrm{b}(\AA)$ & 4.883 & $4.858(4.968)$ \\
$\mathrm{c}(\AA)$ & 4.883 & $8.042(8.098)$ \\
Volume $\left(\AA^{3}\right)$ & 82.340 & 164.456 \\
$\mathrm{Z}$ & 2 & 1 \\
$\mathrm{~B}(\mathrm{GPa})$ & 218.90 & 222.496 \\
$\mathrm{C}_{11}$ & 316.256 & 358.613 \\
$\mathrm{C}_{12}$ & 170.230 & 180.066 \\
$\mathrm{C}_{44}$ & 96.075 & 91.652 \\
$\mathrm{C}_{33}$ & - & 347.149 \\
$\mathrm{C}_{13}$ & - & 146.081 \\
$\mathrm{C}_{\mathrm{s}}$ & 86.075 & 93.721 \\
$\rho$ & 11.0766 & 11.7201 \\
$v_{l}(\mathrm{~m} / \mathrm{s})$ & 5488.5230 & 5447,6170 \\
$v_{t}(\mathrm{~m} / \mathrm{s})$ & 2787.6312 & 2827,834 \\
$v_{m}(\mathrm{~m} / \mathrm{s})$ & 3123.573 & 3164,9355 \\
$\Theta_{\mathrm{D}}(\mathrm{K})$ & 378 & 394 \\
$\mathrm{Y}$ & 230.119 & 246.595 \\
$v$ & 0.32479 & 0.31557 \\
\hline
\end{tabular}



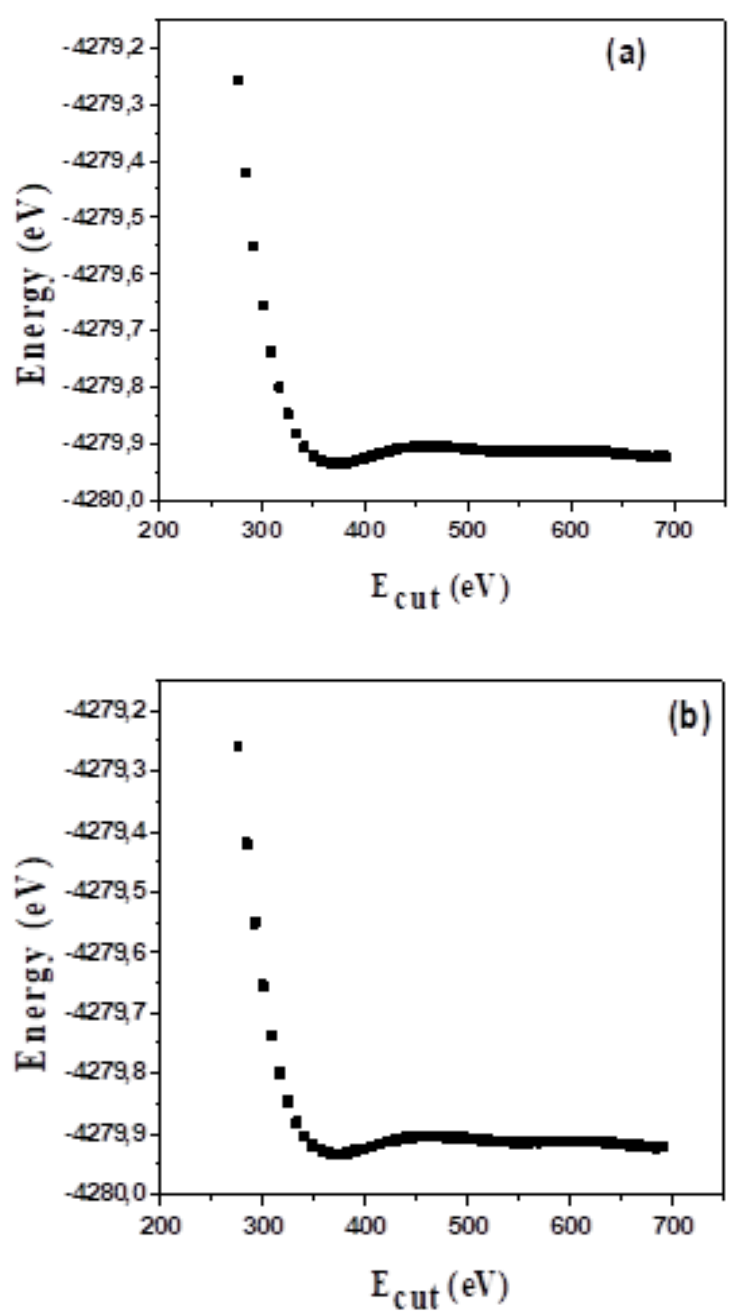

Fig. 2. Energy versus $E_{\text {cut }}$ in cubic (a) and hexagonal (b) structure. 


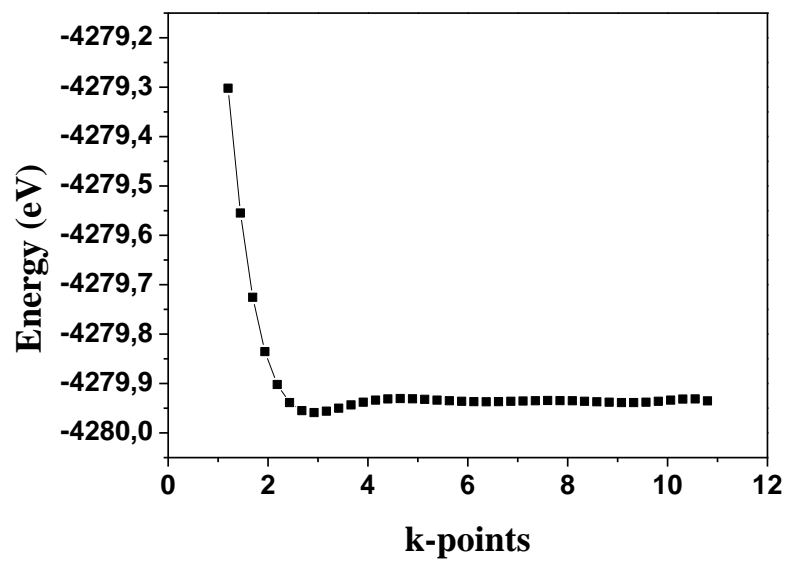

Fig. 3. Energy versus number of $k$ points of our computed compounds.
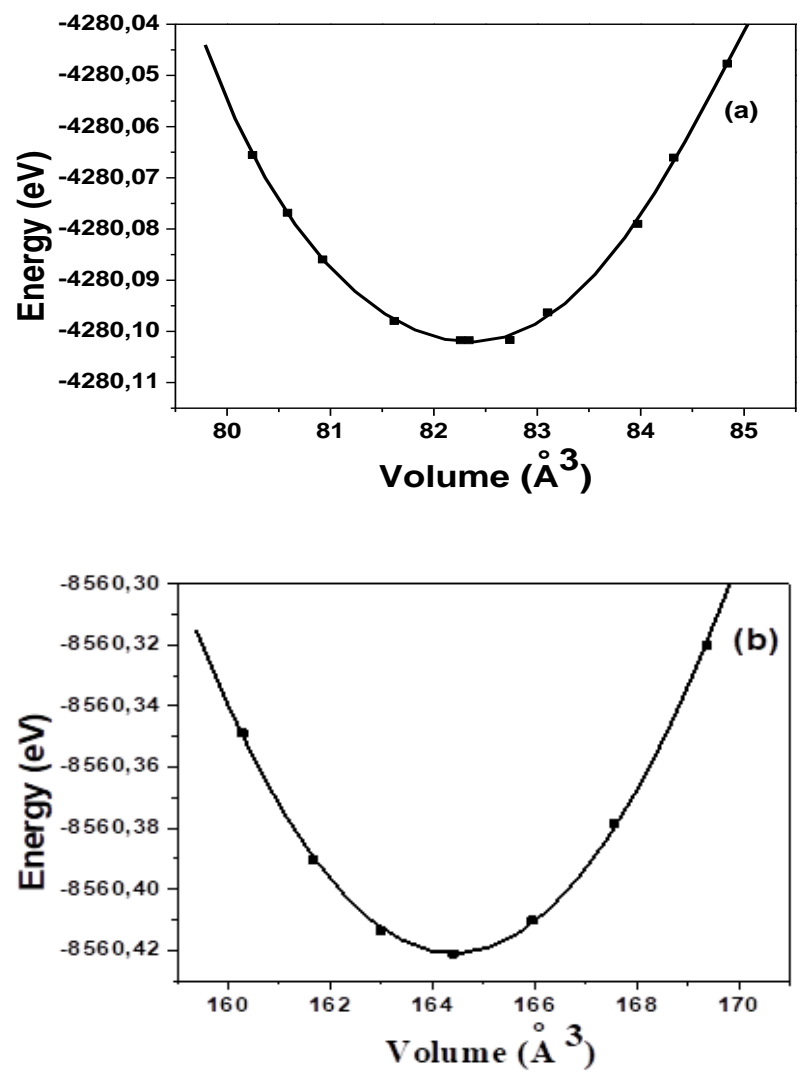

Fig. 4. Energy versus volume for $\mathrm{Fe}_{2} \mathrm{Hf}$ in cubic (a) and hexagonal (b) structure. 


\section{Elastic constants}

The elastic constants for the system are established using a Taylor series expansion of the total energy, $\mathrm{E}(\mathrm{V})$, in comparison to a modest deformation $\delta$ of the lattice unit cell volume $\mathrm{V}$. The energy of system limitation is expressed as follow [19]:

$$
E(V, \delta)=E\left(V_{0}, 0\right)+V_{0}\left[\sum_{i} \tau_{i} \xi_{i} \delta_{i}+\frac{1}{2} \sum_{i j} C_{i j} \delta_{i} \xi_{i} \delta_{j}\right]
$$

Where $E\left(V_{0}, 0\right)$ is the energy of an unstrained system with $V_{0}$, is a stress tensor element, and is a factor to account for the Voigt index. Asymmetric and isotropic materials have between 21 and 2 independent elastic constants, while cubic and hexagonal crystals have 3 and 5 independent elastic constants, respectively. $\mathrm{C}_{11}, \mathrm{C}_{44}$, and $\mathrm{C}_{12}$ for cubic crystals and $\mathrm{C}_{11}, \mathrm{C}_{33}, \mathrm{C}_{44}, \mathrm{C}_{12}$, and $\mathrm{C}_{13}$ for hexagonal crystals are the three independent elastic constants. The first-order and second-order derivatives of the potential are well-known for giving forces and elastic constants. As a result, checking the accuracy of the calculations for forces and elastic constants is critical. Let us recall that the effect of pressure on elastic constants is critical for understanding interatomic interactions, mechanical stability, and phase transition mechanisms, at the very least. For cubic and hexagonal $\mathrm{Fe}_{2} \mathrm{Hf}$ structures, the relevant bulk moduli are found as a function of pressure up to $50 \mathrm{GPa}$. When pressure is increased as shown in Fig. 5, all elastic constants, as well as bulk moduli B, increase linearly.

$$
B=\left(C_{11}+2 C_{12}\right) / 3
$$

The bulk modulus value estimated using the second approach agrees with the bulk modulus calculated using the first method. The generalized elastic stability criterion for $\mathrm{Fe}_{2} \mathrm{Hf}$ in a cubic crystal is as follows:

$$
\begin{array}{ll}
\left(\mathrm{C}_{11}+2 \mathrm{C}_{12}\right) / 3>0 & \mathrm{C}_{44}>0 \\
\left(C_{11}-C_{12}\right) / 2>0 &
\end{array}
$$

For $\mathrm{Fe}_{2} \mathrm{Hf}$ in a hexagonal crystal, the elastic stability criteria $[20,21]$ are:

$$
\begin{aligned}
& C_{11}>0, C_{33}>0, C_{44}>0, C_{66}>0, C_{11}-C_{12}>0, C_{11}+C_{33}+C_{12}>0,\left(C_{11}+\right. \\
& \left.C_{12}\right) C_{33}-2 C_{13}^{2}>0
\end{aligned}
$$

The fact that all of the foregoing conditions are violated by the elastic constants of $\mathrm{Fe}_{2} \mathrm{Hf}$ in the cubic [hexagonal] crystal suggests that it is instable [stable]. The shear anisotropy factors $\mathrm{A}(\mathrm{Cij})=0.88$ and $\mathrm{kc} / \mathrm{ka}=1.22$ for $\mathrm{Fe}_{2} \mathrm{Hf}$ with hexagonal structure, the $\mathrm{B}$ and $\mathrm{G}$ for hexagonal structures are calculated as follows [22,23]:

$$
\begin{aligned}
& B=\frac{2}{9}\left(C_{11}+C_{12}+2 C_{13}+\frac{1}{2} C_{33}\right) \\
& G=\left\{C_{44}\left[C_{44}\left(C_{11}-C_{12}\right) / 2\right]^{1 / 2}\right\}^{1 / 2}
\end{aligned}
$$




$$
\begin{aligned}
E & =\frac{\left[C_{33}\left(C_{11}+C_{12}\right)-2 C_{13}^{2}\right]\left(C_{11}-C_{12}\right)}{C_{11} C_{33}-C_{13}^{2}} \\
A & =\frac{2 C_{44}}{C_{11}-C_{12}} \\
v & =\frac{C_{12} C_{33}-C_{13}^{2}}{C_{11} C_{33}-C_{13}^{2}}
\end{aligned}
$$
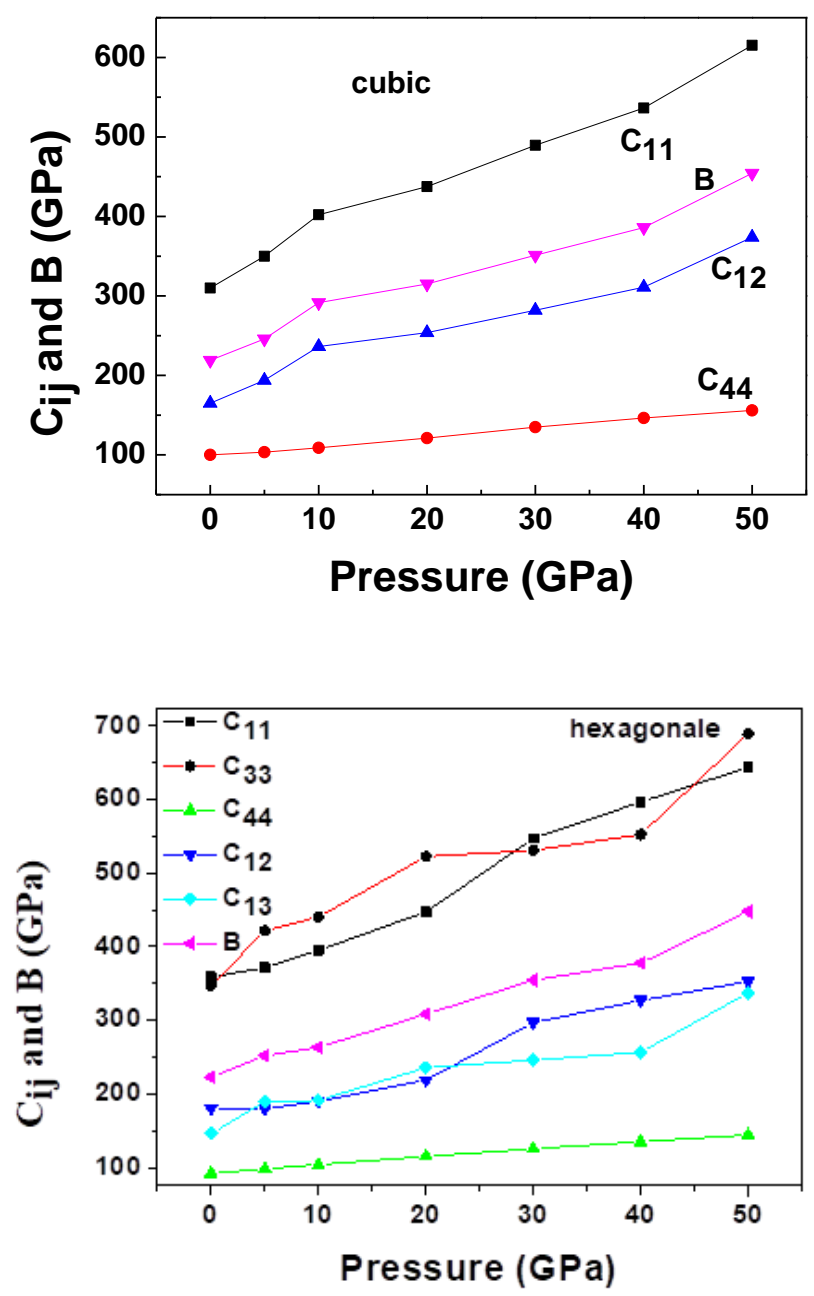

Fig. 5. The elastic constants of the cubic and hexagonal structures of $\mathrm{Fe}_{2} \mathrm{Hf}$ compound under pressure up to $50 \mathrm{GPa}$ at $0 \mathrm{~K}$.

We can conclude that the bulk modulus is $219 \mathrm{GPa}$ for cubic $\mathrm{Fe}_{2} \mathrm{Hf}$ and 222 $\mathrm{GPa}$ for hexagonal one. All values are exceptionally high, exceeding or matching other hard materials, including boron carbide $\left(\mathrm{B}_{4} \mathrm{C}, 200 \mathrm{GPa}\right)$, silicon carbide $(\mathrm{SiC}, 248 \mathrm{GPa})$, 
sapphire $\left(\mathrm{Al}_{2} \mathrm{O}_{3}, 252 \mathrm{GPa}\right)$, and cubic boron nitride ( $c$-BN, $\left.367 \mathrm{GPa}\right)$ [24]. Pugh [25] proposed the $\mathrm{B} / \mathrm{G}$ ratio to represent a measure of a "machine able behavior". A high $\mathrm{B} / \mathrm{G}$ value (2.444 for hexagonal $\mathrm{Fe}_{2} \mathrm{Hf}$ type structure) is linked to ductility, while a low one is linked to brittleness. Around 1.75 is the crucial number that distinguishes between ductile and brittle behavior. Diamond, for example, has a B/G of 0.80 [26], whereas aluminum, cobalt, rhodium, and iridium, respectively, have B/G ratios of 2.74 , $2.43,1.77$, and 1.74 . We find a $\mathrm{B} / \mathrm{G}$ estimated ratio of 2.44 for the hexagonal structure of $\mathrm{Fe}_{2} \mathrm{Hf}$ combination. Due to the fact that $\mathrm{Fe}_{2} \mathrm{Hf}$ compounds are ductile; furthermore, the elastic constants data $\left(\mathrm{C}_{11}-\mathrm{C}_{12}>0\right)$ can be used to forecast the hexagonal structure's mechanical stability at $0 \mathrm{GPa}$. The elastic constants of pure $\mathrm{Fe}_{2} \mathrm{Hf}$ are reported in Table 1. The average sound velocity $\mathrm{V}_{\mathrm{m}}[26,27]$ can be used to calculate the Debye temperature.

$$
V_{m}=\left[\frac{1}{3}\left(\frac{2}{V_{s}^{3}}+\frac{1}{V_{l}^{3}}\right)\right]^{-1 / 3}
$$

The shear and longitudinal sound velocities are $\mathrm{V}_{\mathrm{s}}$ and $\mathrm{V}_{\mathrm{l}}$.

In Table 1, the longitudinal, transverse, and average sound velocities, as well as the Debye temperature of $\mathrm{Fe}_{2} \mathrm{Hf}$ have been determined. We have estimated the sound velocities and Debye temperature for the $\mathrm{Fe}_{2} \mathrm{Hf}$ compounds from our elastic constants at $0 \mathrm{GPa}$ and $0 \mathrm{~K}$. The experimental and estimated sound velocities and Debye temperatures are comparable.

\section{Electronic structure}

The electronic characteristics of $\mathrm{Fe}_{2} \mathrm{Hf}$ are studied in this section. At equilibrium lattice constants; Fig. 6 displays the (DOS) for our compound configurations. Only the Fermi energy level's vicinity is shown here. Except for a few changes, the DOS profiles of $\mathrm{Fe}_{2} \mathrm{Hf}$ are identical throughout the energy range. Near the Fermi level, the DOS is primarily derived from the M-d bands $\mathrm{M}\left(\mathrm{Fe}_{2} \mathrm{Hf}\right)$ in cubic and hexagonal structures, implying that our compounds are all conductive and that the transition metal's d bands play a dominant role in electrical transport. This phenomenon is particularly pronounced in hexagonal structures. In cubic and hexagonal $\mathrm{Fe}_{2} \mathrm{Hf}$, the DOS at the Fermi level $n\left(E_{F}\right)$ is predicted to be 10.69 states/eV unit cell for cubic $\mathrm{Fe}_{2} \mathrm{Hf}$ and $20.11 \mathrm{eV}$ for hexagonal $\mathrm{Fe}_{2} \mathrm{Hf}$, suggesting the metallic material. 

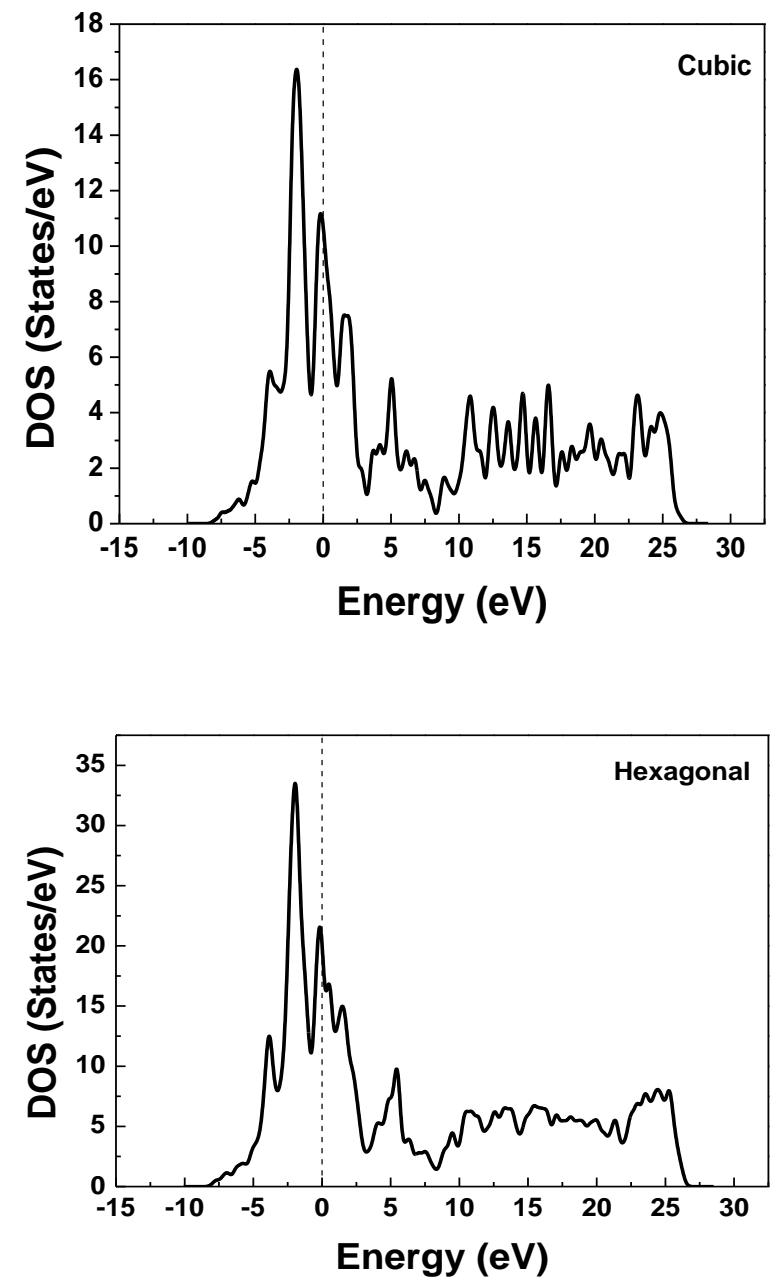

Fig. 6. The total electronic density of state for $\mathrm{Fe}_{2} \mathrm{Hf}$ in cubic and hexagonal structures.

\section{Thermodynamic properties}

A study of the effects of chemistry and crystal structure must be performed for motors with operating temperatures in the region of $2000^{\circ} \mathrm{C}$ that will require materials that can withstand. Intermetallic compounds with high melting temperatures are candidates for these applications. Thermodynamics is mainly based on temperature and entropy, which is the degree of disorganization of the material. Physical properties under pressures and temperatures have important meanings to accelerate the understanding and synthesis of $(c, h)-\mathrm{Fe}_{2} \mathrm{Hf}$ structures. The investigation of the thermal capacity of crystals is an interesting subject in solid state physics because it enters many applications, and provides essential information on its vibratory properties. According 
to the standard theory of elastic continuum, two limiting cases are correctly predicted. At sufficiently low temperatures, the thermal capacity $C_{V}$ is proportional to $T^{3}$. At high temperature, $C_{V}$ tends to the limit Petit and Dulong. Applying the quasi-harmonic Debye model to the $(c, h)-\mathrm{Fe}_{2} \mathrm{Hf}$ structures, we calculated the thermal capacity $C_{V}$, and the Debye temperature $\Theta$ at different temperatures. Now we investigate the dependences of bulk modulus B on temperature T and pressure P. B is plotted in Fig. 7.
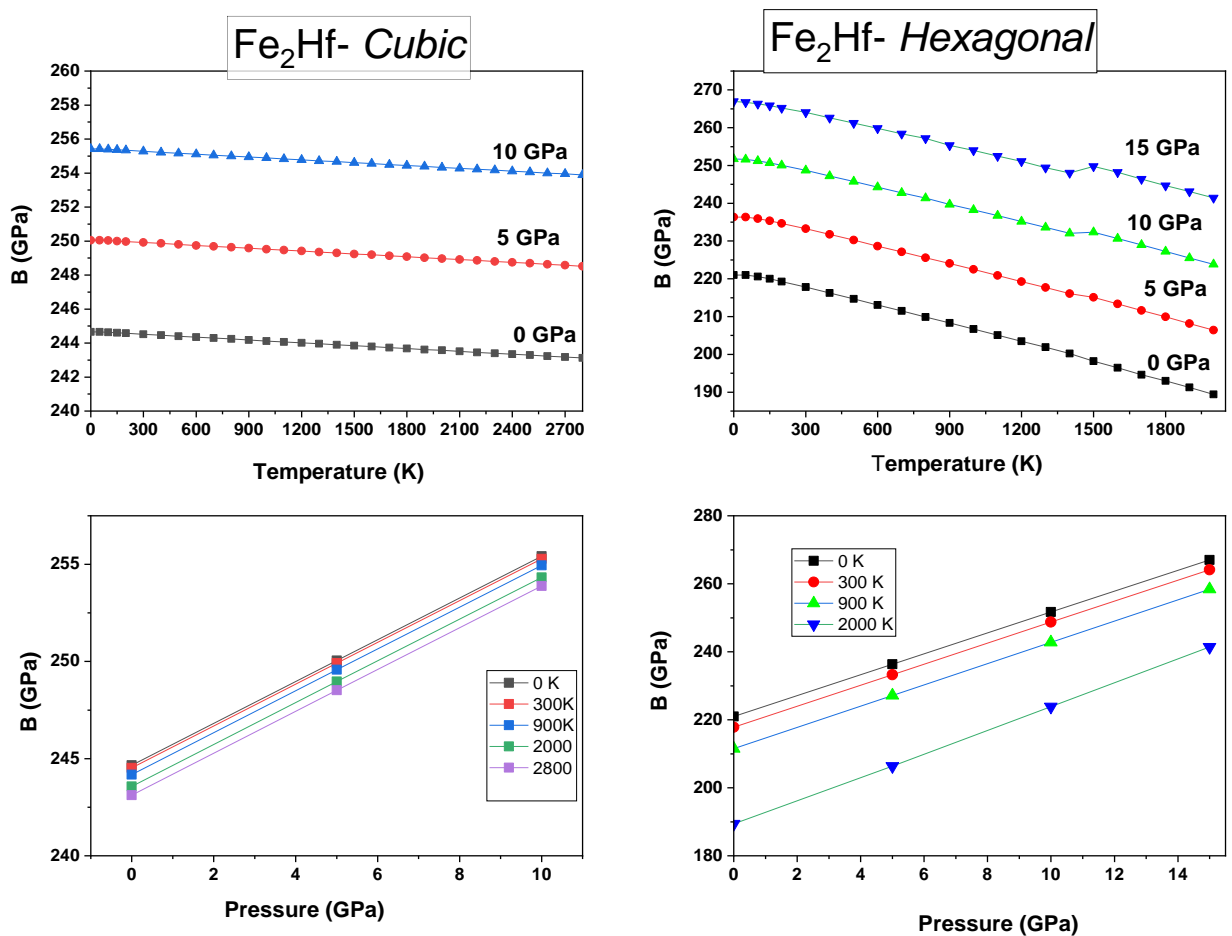

Fig. 7. Variation of bulk modulus with temperature $\mathrm{T}$ and pressures for $\mathrm{c}-\mathrm{Fe}_{2} \mathrm{Hf}$ and $\mathrm{h}$ $\mathrm{Fe}_{2} \mathrm{Hf}$ (upper panel) respectively.

The bulk modulus $B$ decreases with increasing temperature $\mathrm{T}$ in a quasi-linear manner for both $c$ - $\mathrm{Fe}_{2} \mathrm{Hf}$ and $h$ - $\mathrm{Fe}_{2} \mathrm{Hf}$ structures. The calculated $\mathrm{B}_{0}$ at $(\mathrm{T}=0 \mathrm{~K})$ is $244.5 \mathrm{GPa}$ for $c$ - $\mathrm{Fe}_{2} \mathrm{Hf}$ and $222 \mathrm{GPa}$ for $h$ - $\mathrm{Fe}_{2} \mathrm{Hf}$ structures. We can see that the $B$ decreases [increases] with temperature (upper panel) [P] [lower panel] at a given pressure [T] for both $c-\mathrm{Fe}_{2} \mathrm{Hf}$ (slowly decreases) and $h-\mathrm{Fe}_{2} \mathrm{Hf}$ structures. The resulting Debye temperature $\Theta$ versus temperature [P] (upper panel) [lower panel] for $c$ - $\mathrm{Fe}_{2} \mathrm{Hf}$ and $h$ $\mathrm{Fe}_{2} \mathrm{Hf}$ structures is shown in Fig. 8. 

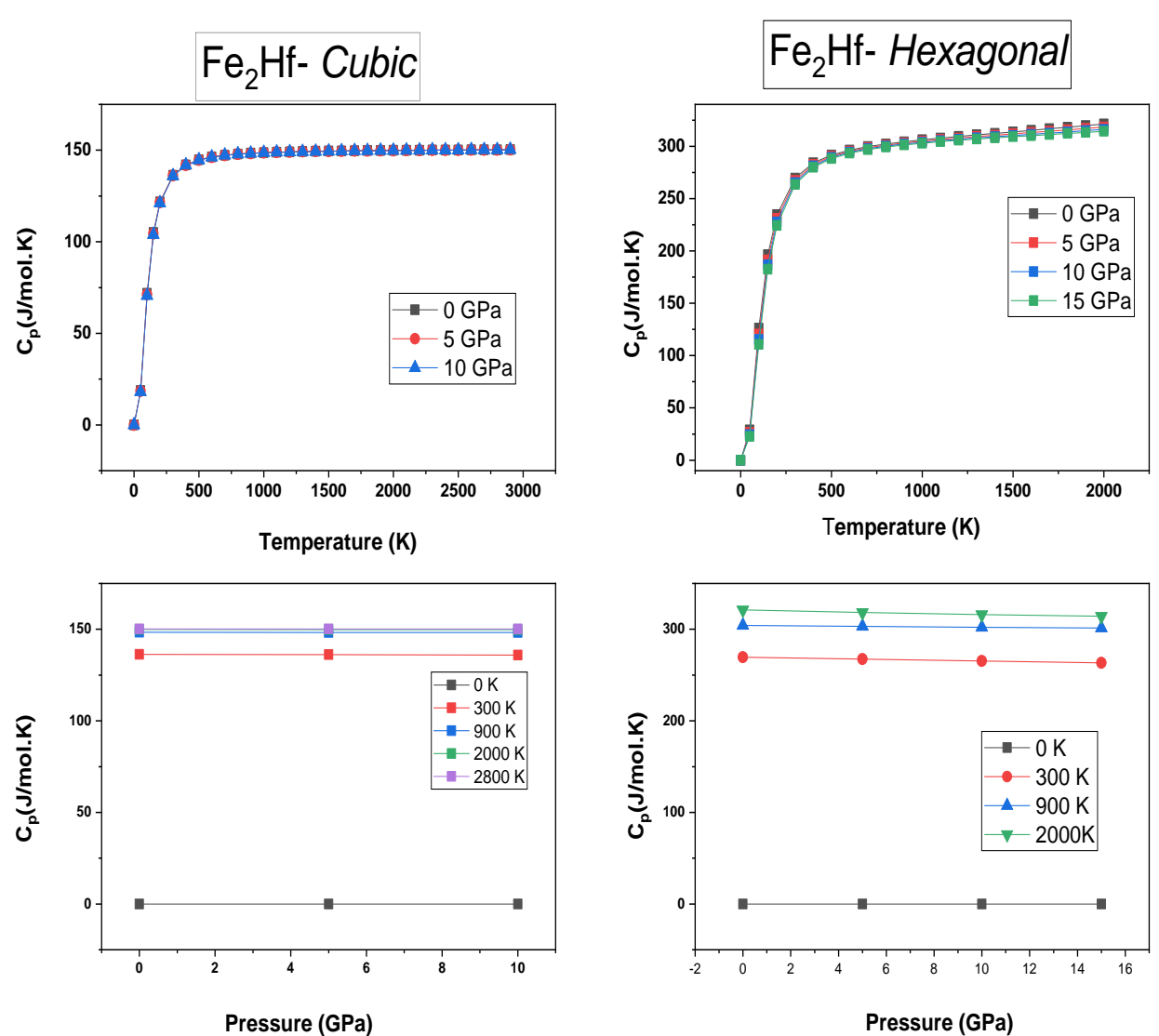

Fig. 8. Variation of constant pressure heat capacity $C_{P}$ with temperature $T$ and pressures for $\mathrm{c}-\mathrm{Fe}_{2} \mathrm{Hf}$ and $\mathrm{h}-\mathrm{Fe}_{2} \mathrm{Hf}$ (upper panel) respectively.

From the quasi-harmonic Debye model, we obtained the Debye temperature $\Theta=415.5$ $\mathrm{K}$ and $458 \mathrm{~K}$ at $\mathrm{P}=0 \mathrm{GPa}$ and $\mathrm{T}=0 \mathrm{~K}$ for $c-\mathrm{Fe}_{2} \mathrm{Hf}$ and $h-\mathrm{Fe}_{2} \mathrm{Hf}$ structures Fig. 9. The heat capacity $\mathrm{C}_{\mathrm{P}}$ and $\mathrm{C}_{\mathrm{V}}$, represents the heat absorbed by the crystal at constant pressure or constant volume necessary to raise the temperature of one mole of a pure substance by one degree $\mathrm{K}$ generated by this transformation. The heat capacity of a crystal is given by a relation deduced from the vibratory motions of the crystal lattice it is also mandatory for many applications. For solids and liquids, the variation of the PV product with the temperature is negligible. Consequently, in the condensed phase, the volume and constant pressure heat capacities have similar values $\mathrm{C}_{\mathrm{P}} \sim \mathrm{C}_{\mathrm{V}}$ for both $c-\mathrm{Fe}_{2} \mathrm{Hf}$ and $h$ - $\mathrm{Fe}_{2} \mathrm{Hf}$ structures.

In Fig. 10, we see the sharp increase of $C_{P}$ and $C_{V}$ from 0 to $500 \mathrm{~K}$. At high temperature, the $C_{P}$ and $C_{V}$ tends to a constant value $\left(300 \mathrm{~J} . \mathrm{mol}^{-1} \mathrm{~K}^{-1}\right)\left[150 \mathrm{~J} . \mathrm{mol}^{-1} \mathrm{~K}^{-1}\right]$ for $(c-h)$ $\mathrm{Fe}_{2} \mathrm{Hf}$ the so-called Dulong-Petit limit of $3 \mathrm{nk}_{\mathrm{B}}$ value [30]. We can conclude that the

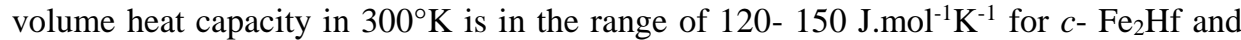
250- $300 \mathrm{~J} \cdot \mathrm{mol}^{-1} \mathrm{~K}^{-1}$ for $h$ - $\mathrm{Fe}_{2} \mathrm{Hf}$. All of the values in this range are extremely high, surpassing or equal those of other hard materials, including silicon oxide $\left(\mathrm{SiO}_{2}, 71.5\right.$ 
J.mol $\left.{ }^{-1} \mathrm{~K}^{-1}\right)$, sapphire $\left(\mathrm{Al}_{2} \mathrm{O}_{3}, 120.5 \mathrm{~J} \cdot \mathrm{mol}^{-1} \mathrm{~K}^{-1}\right)$, and $\left(\mathrm{Cr}_{2} \mathrm{O}_{3}, 125.1 \mathrm{~J} . \mathrm{mol}^{-1} \mathrm{~K}^{-1}\right)$ and approaching that of diamond $\left(B_{0}=442 \mathrm{GPa}\right)$. The volume expansion coefficient $\alpha_{\mathrm{o}} \mathrm{f}(c$, $h$ )- $\mathrm{Fe}_{2} \mathrm{Hf}$ structures as function of $\mathrm{T}$ (upper panel) and $\mathrm{P}$ (lower panel) is plotted in Fig. 11. At $0 \mathrm{GPa}$ and $300 \mathrm{~K}, \alpha=0.41242 \times 10^{-5} \mathrm{~K}^{-1}$ for $c-\mathrm{Fe}_{2} \mathrm{Hf}$ and $0.42234 \times 10^{-5} \mathrm{~K}^{-1}$ for $h$ - $\mathrm{Fe}_{2} \mathrm{Hf}$. It is shown that, for a given $\mathrm{P}[\mathrm{T}], \alpha$ increases [constant] with T [P], especially at $0 \mathrm{GPa}$ and gradually tends to a linear increase at high $\mathrm{T}$, for $c-\mathrm{Fe}_{2} \mathrm{Hf}$ and slightly different for $h-\mathrm{Fe}_{2} \mathrm{Hf}$ structures. We show in Fig. 12, the entropy function of the temperature at different pressures and of the pressure at different temperatures of the two types of c-FeHf and h-Fe2Hf structures of the compound. We show that the entropy increase parabolically with increasing temperature. We notice that these curves have the same shape except the existence of q slight offset at high temperature for the case of the hexagonal type (upper panel).
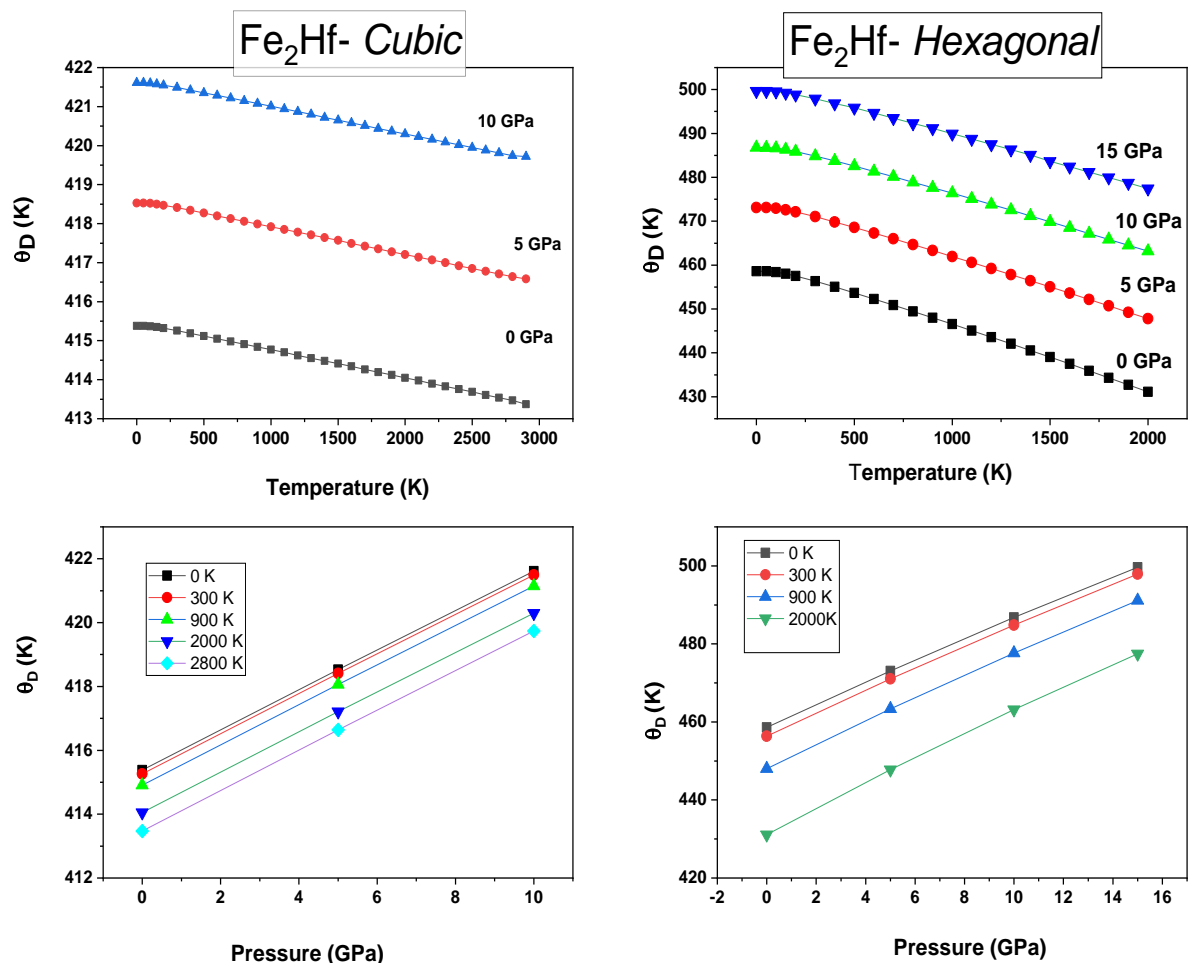

Fig. 9. Variation of Debye temperature with temperature $\mathrm{T}$ and pressures for $\mathrm{c}-\mathrm{Fe}_{2} \mathrm{Hf}$ and $h-\mathrm{Fe}_{2} \mathrm{Hf}$ (upper panel), respectively. 

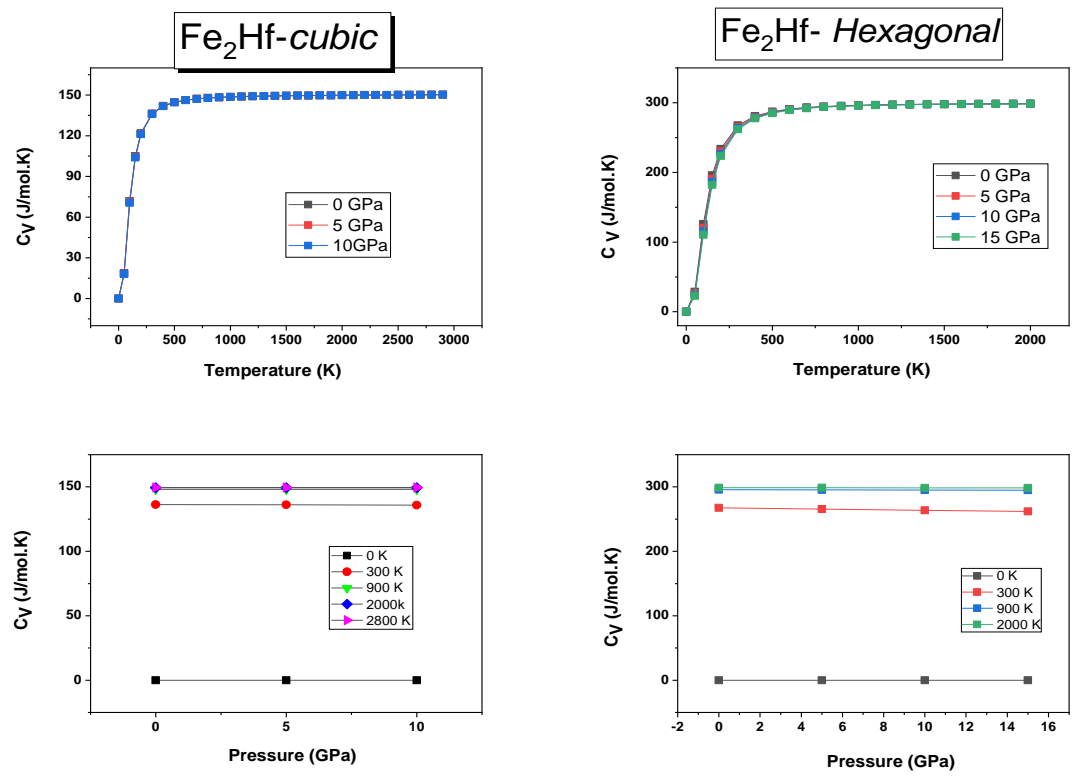

Fig. 10. Variation of constant volume heat capacity $C_{V}$ with temperature $T$ and pressures for $\mathrm{c}-\mathrm{Fe}_{2} \mathrm{Hf}$ and $\mathrm{h}$ - $\mathrm{Fe}_{2} \mathrm{Hf}$ (upper panel), respectively.
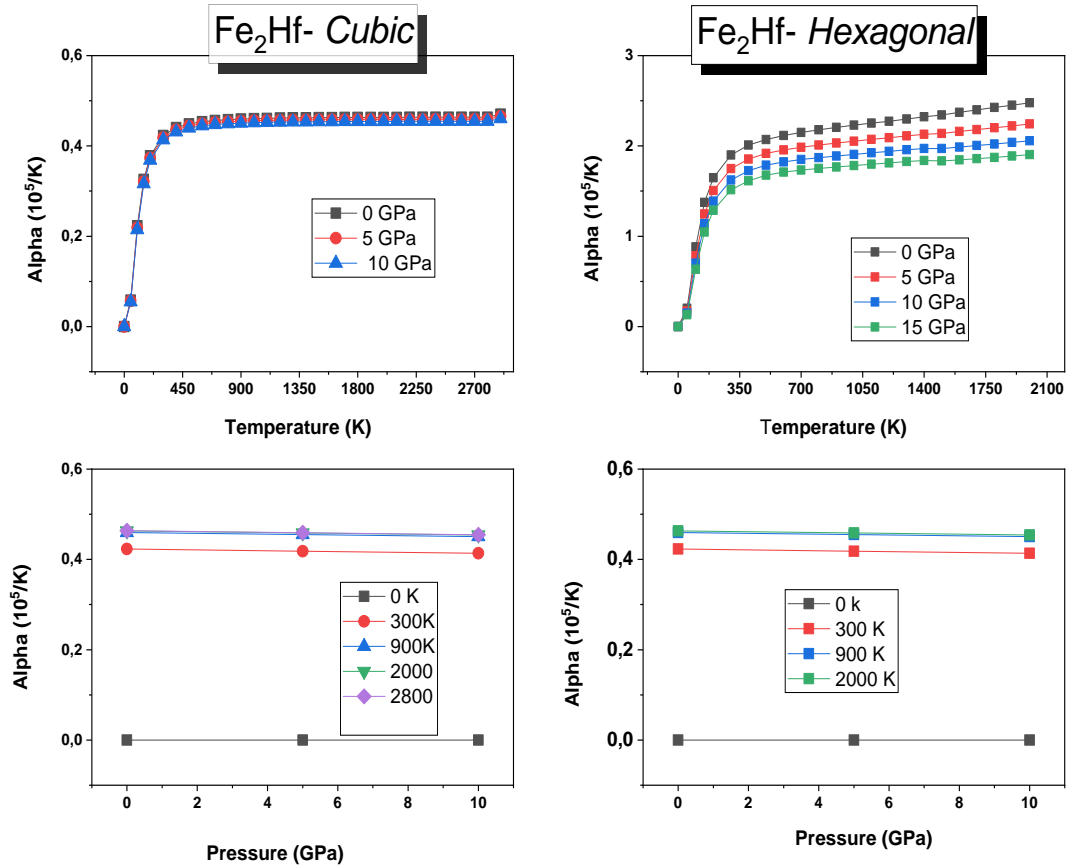

Fig. 11. Variation of volume expansion coefficient $\alpha$ with temperature $T$ and pressures for $\mathrm{c}-\mathrm{Fe}_{2} \mathrm{Hf}$ and $\mathrm{h}-\mathrm{Fe}_{2} \mathrm{Hf}$ (upper panel), respectively. 

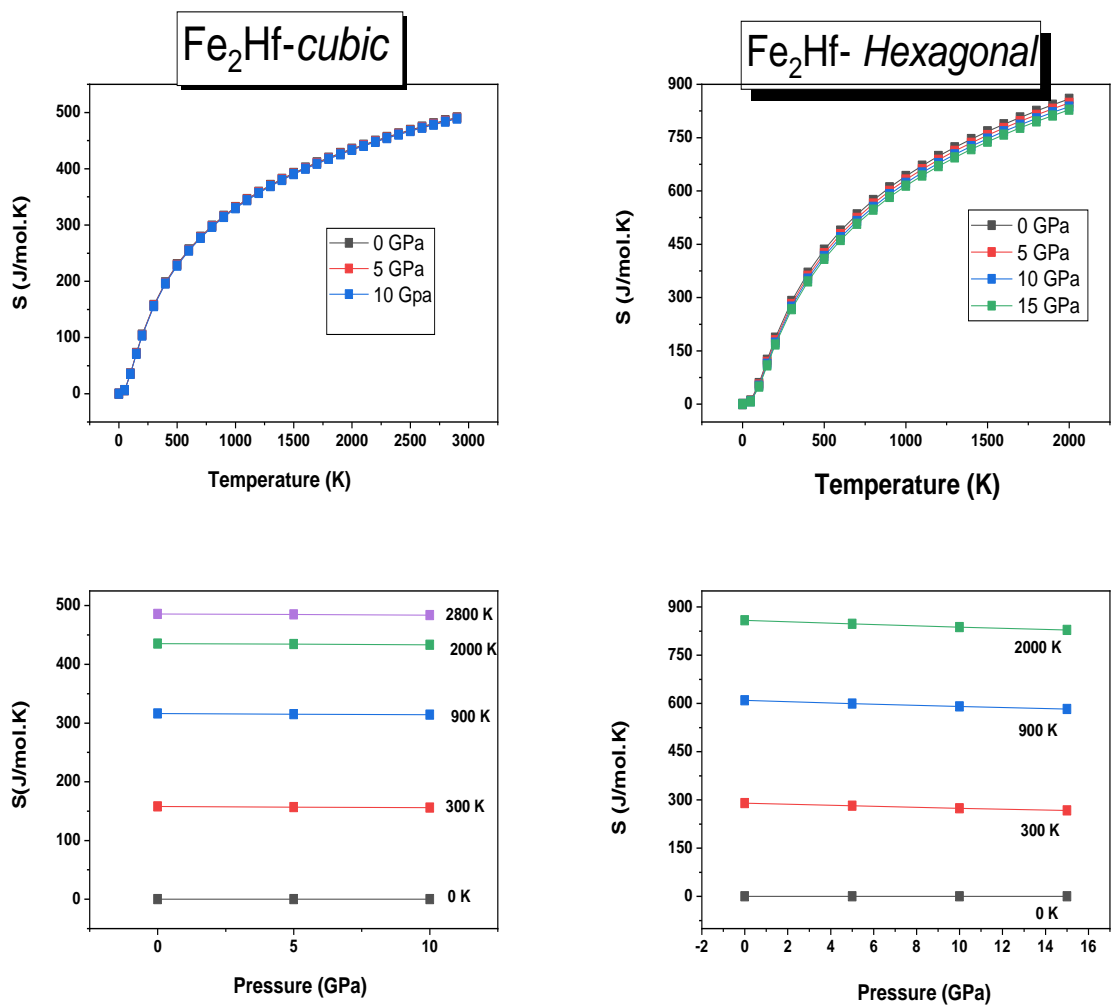

Fig. 12. Variation of entropy $S$ with temperature $\mathrm{T}$ and pressures for $\mathrm{c}-\mathrm{Fe}_{2} \mathrm{H} f$ and $h$ $\mathrm{Fe}_{2} \mathrm{Hf}$ (upper panel), respectively.

\section{Conclusion}

We draw theoretical findings for structural, elastic, mechanical, electrical, and thermodynamic properties of Fe2Hf in the cubic and hexagonal solid phases based on $\mathrm{ab}$ initio total energy calculations. The lattice constants obtained are fairly close to the experimental values. Hexagonal structures are more stable than cubic structures in terms of total energy. The DOS at the Fermi level n(EF) for cubic is 10.69 states/eV unit cell, while the DOS for hexagonal is 20.11 states/eV, indicating metallic material. In general, the molecule with a lower $n(E F)$ is more stable. As a result, the total energy minimum values and the values generated from the total energy minimum agree well. All estimated bulk modulus values are exceptionally high, exceeding or equaling those of other hard materials such as boron carbide (B4C, $200 \mathrm{GPa}$ ), silicon carbide (SiC, 248 $\mathrm{GPa}$ ), sapphire (Al2O3, $252 \mathrm{GPa})$, and cubic boron nitride (CBN, $252 \mathrm{GPa})$ (c-BN, 367 $\mathrm{GPa})$. For the other estimated qualities in this paper, there are no previous computations or experimental data to compare with.

\section{Acknowledgments}

Taif University Research Supporting Project number (TURSP-2020/66), Taif University, Taif, Saudi Arabia. 


\section{References}

[1] Koki Ikeda: Inter J Mater Research, 68 (1977) 195-198.

[2] S. Kobayashi, K. Kimura, K. Tsuzaki: Intermetallics, 46 (2014) 80-84.

[3] S. Kobayashi, T. Hibaru: ISIJ International, 55 (2015) 293-399.

[4] J. Belosevic-Cavor, V. Koteski, N. Novakovic, G. Concas, F. Congiu, G. Spano: Euro Phys J B, 50 (2006) 425-430.

[5] M. Takeyama: Materials Science Forum, 3012 (2007) 539-543.

[6] D. Sholl, J.A. Steckel, Density functional theory: a practical introduction, John Wiley \& Sons (2011) 17-25.

[7] K.P. Skokov, O. Gutfleisch: Scripta Materialia, 154 (2018) 289-294.

[8] W. Kohn, L.J. Sham: Physical review, 140 (1965) 1133-1138.

[9] J.P. Perdew, K. Burke, M. Ernzerhof: Phy rev letters, 77 (1996) 3865-3871.

[10] O.Y. Vekilova, B. Fayyazi, K.P. Skokov, O. Gutfleisch, C. Echevarria-Bonet, J.M. Barandiaron, A. Kovacs, J. Fischbacher, T. Schrefl, O. Eriksson: Phy Rev B, 99 (2019) 024421-024429.

[11] G. Kresse, D. Joubert: Phy Rev B, 59 (1999) 1758-1763.

[12] D.J. Chadi, M.L. Cohen: Phy Rev B, 8 (1973) 5747-5754.

[13] D. Goll, T. Gross, R. Loeffler, U. Pflanz, T. Vogel, A. Kopp, T Grubesa, G. Schneider Hard: Phy Sta Solidi RRL, 11 (2017) 1700184 (1-4).

[14] A.D. Boese, J.M. Martin, N.C. Handy: J of Chem Phys, 119 (2003) 3005-3014.

[15] A. Tanto, T. Chihi, M.A. Ghebouli, M. Reffas, M. Fatmi, B. Ghebouli: Resu in Phy 9 (2018) 763-770.

[16] F. Weber, L. Pintschovius, W. Reichardt, R. Heid, K.-P.Bohnen, A. Kreyssig, D. eznik, K. Hradil: Phy Rev B, 89 (2014) 10450 (1-13).

[17] M. D. Segall, P.J.D. Lindan, M.J. Probert, C.J. Pickard, P.J. Haspin, S.J. Clark, M.C. Payne: J of Phys Cond Matter, 14 (2002) 2717-2744.

[18] J.P. Perdew, S. Burke, M. Ernzerhof: Phys Rev Letters, 80 (4) (1998) 891-891.

[19] L. Fast, J M. Wills, B. Johansson and O. Eriksson: Phys Rev B, 51 (1995) 17431-17438.

[20] M. Born, K. Huang: Dynamical Theory of Crystal Lattices, Clarendon, Oxford, (1956) 120-124.

[21] Q.K. Hu, Q.H. Wu, Y.M. Ma, L.J. Zhang, Z.Y. Liu, J.L. He, H. Sun, H.T. Wang, Y.J. Tian: Phys Rev B, 73 (2006) 214116 (1-5).

[22] P. Ravindran, L. Fast, P. A. Korzhavyi, B. Johansson, J. Wills and O. Eriksson: J of Appl Phys, 84 (1998) 4891-4904.

[23] C.F. Cline, H.L. Dunegan, G.W. Henderson: J of Appl Phys, 38 (1967) 19441948.

[24] J. M. Leger, J. Haines, M. Schmidt, J.P. Petitet, A.S. Periera, J.A.H. Da Jornada: Nature, 383 (1996) 401.

[25] S.F. Pugh: Philos Mag, 45 (1954) 823-843.

[26] J. Haines, J.M. leger, G. Bocquillon: Ann Rev of Mater Res, 31 (2001) 1-23.

[27] O.L. Anderson: J Phys Chem of Sol, 24 (7) (1963) 909-917.

[28] R. Hill: Proc. Soc. London A, 65 (1952) 350.

[29] K. B. Panda and K. S. Ravi: Comput Mater Sci, 35 (2006) 134-150.

[30] C. Kittel: Introduction to Solid State Physics, $7^{\text {th }}$ ed. Wiley, New York (1996) $15-21$.

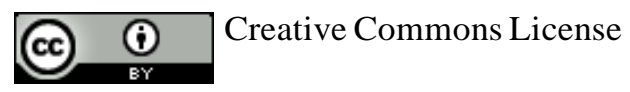

This work is licensed under a Creative Commons Attribution 4.0 International License. 